\title{
The Roles of Vitrification of Stabilizers/Matrix Formers for the Redispersibility of Drug Nanocrystals After Solidification: a Case Study
}

\author{
PengFei Yue, ${ }^{1,3}$ MingSheng Xiao, ${ }^{2}$ YuanBiao Xie, ${ }^{1}$ YueQin Ma, ${ }^{1,2}$ YongMei Guan, ${ }^{1}$ ZhenFeng Wu, \\ PengYi Hu, ${ }^{1}$ and YaQi Wang ${ }^{1}$
}

Received 27 August 2015; accepted 30 November 2015; published online 21 December 2015

\begin{abstract}
To elucidate the roles of vitrification of stabilizers/matrix formers for the redispersibility of drug nanocrystal powder after solidification at storage stress, the influence of different drying methods and storage stresses on stability of drug nanocrystals was systemically investigated. A poorly soluble drug, baicalin, used as model drug was converted into baicalin nanocrystals (BCN-NC). The residual moisture contents of BCN-NC were applied at two different stress conditions defined as "conservative" $(<1 \%)$ and "aggressive" ( $>1 \%)$, respectively. The influence of different stabilizers, matrix formers, and storage stresses on the redispersibility of BCN-NC powder was systemically investigated, respectively. The results showed that storage stresses had significantly influence the redispersibility of BCN-NC. Aggressive storage temperature and residual moisture could be unfavorable factors for stability of drug nanocrystals, due to the exacerbation of aggregation of $\mathrm{BCN}-\mathrm{NC}$ induced by vitrification. It was demonstrated that vitrification of spray-dried BCN-NC was dependent on temperature and time. The polymeric stabilizers hydroxypropylmethylcellulose (HPMC) and sodium carboxymethyl starch (CMS-Na) with high glass transition temperature $\left(T_{\mathrm{g}}\right)$ played more important role in protecting the $\mathrm{BCN}-\mathrm{NC}$ from breakage during storage, compared to the surfactants Tween 80 , D- $\alpha$-tocopherol acid polyethylene glycol 1000 succinate (TPGS), or RH 40. Besides, the polyvinylpyrrolidone K30 (PVP K30) and lactose with high $T_{\mathrm{g}}$ were effective matrix formers for preserving the redispersibility of BCN-NC. It was concluded that the vitrification transition of stabilizers/matrix formers could be responsible for aggregation of drug nanocrystals during storage, which was a time-dependent process. The suitable residual moisture contents (RMC) and $T_{\mathrm{g}}$ were very important for preserving the stability of drug nanocrystals during storage.
\end{abstract}

KEY WORDS: baicalin; nanocrystals; redispersibility; storage stress; vitrification.

\section{INTRODUCTION}

Nanosuspensions (NS) are generally produced in liquid media in which drug particles size is less than $1 \mu \mathrm{m}$ and stabilized by surfactants or polymers. NS has some unique advantages that enhance the solubility and dissolution velocity of poorly soluble drugs due to their small particle size and high surface area $(1,2)$. But liquid NS has a significant drawback of poor stability, which is often found in the range of several months $(3,4)$. Nanocrystals (NC) are conversed from NS by means of freeze-drying and spray-drying (5-7), are composed of drug as well as stabilizers, and can be easily reconstituted into original NS states spontaneously followed by rehydration in vitro or in the gastrointestinal tract (redispersibility), if they

MingSheng Xiao and PengFei Yue contributed to the work equally as joint first authors.

\footnotetext{
$\overline{{ }^{1} \text { Key Lab of Modern Preparation of TCM, Ministry of Education, }}$ Jiangxi University of Traditional Chinese Medicine, Nanchang, China.

${ }^{2}$ 94th Hospital of People's Liberation Army, Nanchang, China.

${ }^{3}$ To whom correspondence should be addressed. (e-mail: ypfpharm@126.com)
}

were not subjected to irreversible aggregation during solidification (8).

Redispersibility stability is an important requirement in development of drug nanocrystals, which can provide evidence on how the quality of drug nanocrystals varies with time under the influence of a variety of storage conditions, such as temperature, humidity, and light (9). The drug nanocrystals are usually regarded as having excellent stability if their redispersibility does not change significantly during storage. However, the storage process generates a series of stresses from internal (due to stabilizers or residual moisture) and external factors (due to heat) at various storage conditions, which could inevitably destabilize nanocrystals and impact on the redispersibility of nanocrystals (Fig. 1). Previous research in this field has shown that the stabilizer played an important role in stabilizing drug nanosuspensions $(10,11)$. The key question on what roles a stabilizer must exhibit to destabilize nanocrystals during storage still needs to be systemically investigated.

It was well known that after converting nanosuspensions into nanocrystals, all stabilizers/matrix formers should be theoretically converted into the solid or glassy state where the drug nanocrystals were immobilized and "mobility" might be 


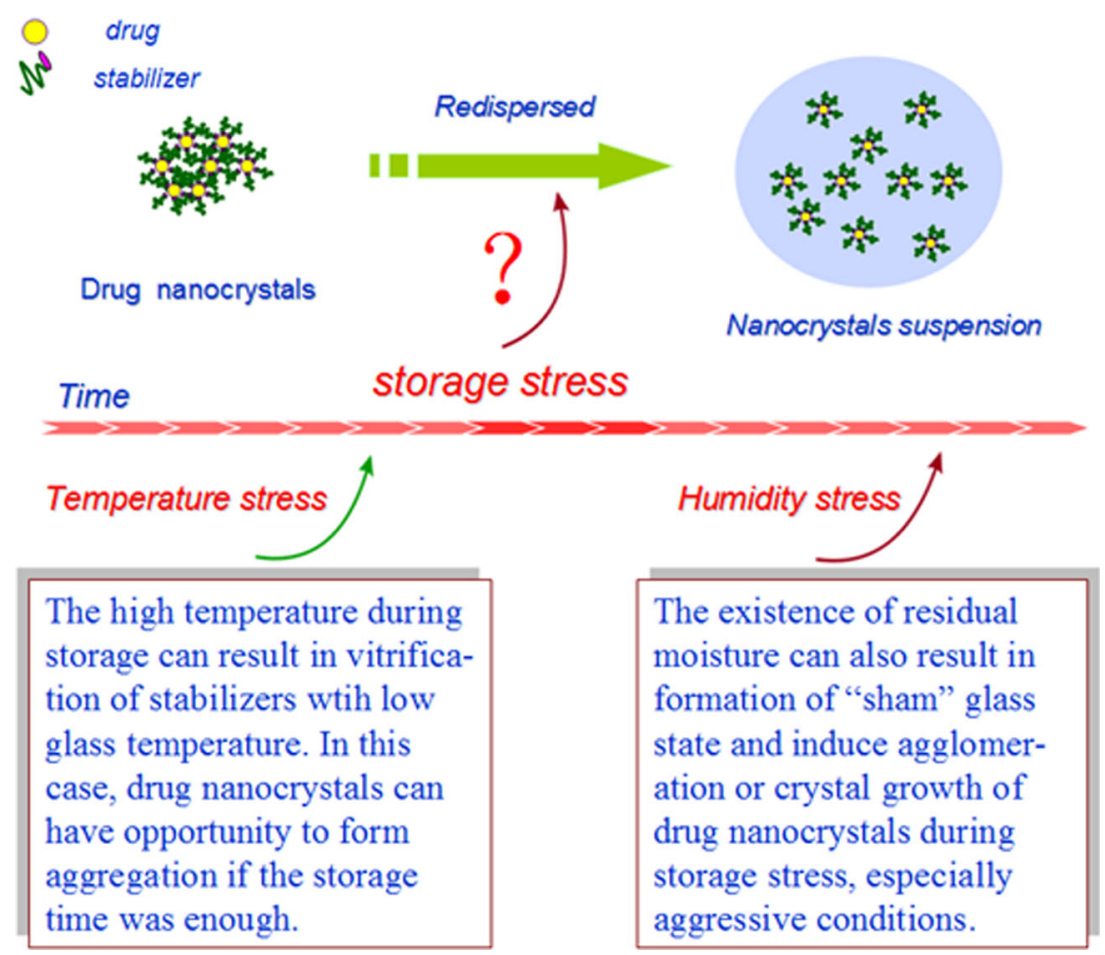

Fig. 1. Schematic illustrations of storage stress involved in storage of drug nanocrystals

reduced to a minimum (12). That is said that the stabilizers/ matrix formers should remain as a solid or glassy state, which might be a prerequisite for the stability of drug nanocrystals.

The glass transition temperature $\left(T_{\mathrm{g}}\right)$ is defined as the temperature at which an amorphous system changes from the glassy to the rubbery state $(13,14)$. Theoretically, in the glassy state, the high viscosity of the matrix does not allow the aggregation of nanocrystals. However, the stabilizers/ dispersants with low $T_{\mathrm{g}}$ could be subjected to various stresses (due to heat or humidity) and convert into the rubbery state during storage, the nanocrystal particles would have opportunity to form some aggregates again. For example, D- $\alpha$-tocopherol acid polyethylene glycol 1000 succinate (TPGS) and Tween 80 are naturally viscous liquids and have low glass temperature values. If such materials presented in drug nanocrystals can be converted into the glassy state after solidification, but subsequently changed from the glassy to the rubbery state when storage temperature is higher than $T_{\mathrm{g}}$, then drug nanocrystal particles could not be completely "imprisoned" and again form aggregations. From that point of view, one may expect that even at ambient conditions, individual nanocrystals is mobile, if ambient temperature is more than its glass temperature. The vitrification property of stabilizers/dispersants seems to be responsible for the redispersibility of drug nanocrystals $(15,16)$. But previous study demonstrated that fresh drug nanocrystals stabilized by RH 40 or Tween 80 after spray-drying can completely redisperse into original nanosuspensions, where they did not comprise to high dry temperature (17). A hypothesis is drawn that influences of vitrification of stabilizers/matrix formers on the stability of drug nanocrystals may be dependent on a series of storage stresses, such as time and temperature.

Furthermore, nanocrystals with $T_{\mathrm{g}}$ higher than their storage temperature can be viewed as staying in a stable state.
However, a case may be often neglected that drug nanocrystals also may be freely mobile and not completely immobilized, if the drug nanocrystals powder contains relative high residual moisture. The existence of residual moisture can easily result in "vitrification" of nanocrystals system at storage stress, which might induce agglomeration of nanocrystal particles. But the literature about the effect of residual moisture on the redispersibility of drug nanocrystals is lacking. In view of these considerations, understanding storage stress conditions, which have a strong impact on stability of nanocrystals, is important.

As so far, no attempt has ever been made to understand the influence of storage stress on the redispersibility of drug nanocrystals. As a continuation of our previous work (17), this manuscript aimed to fill this gap and to present an approach for rational design of stable NC during storage. Baicalin (7-Dglucuronic acid-5,6-dihydroxy-flavone) was used as a case study, a typical compound with poor aqueous solubility, which had already been used in research in the past (18-21). Baicalin nanocrystal suspensions (BCN-NS) were prepared by highpressure homogenization. Cremophor EL (RH 40), Tween 80, TPGS, hydroxypropylmethylcellulose (HPMC), and sodium carboxymethyl starch (CMS-Na) were used as steric stabilizers and used either alone or in combination with the matrix formers sucrose, trehalose, lactose, sorbitol, and polyvinylpyrrolidone K30 (PVP K30). The objectives of this manuscript are (1) BCN-NS was converted into baicalin nanocrystals (BCN-NC) via freeze-drying (conservative drying method) and spray-drying (aggressive drying method), respectively. The influence of different drying methods on the stability of BCN-NC was investigated. (2) The influence of the residual moisture contents on the stability of BCN-NC was evaluated to elucidate its importance on the redispersibility of BCN-NC during storage. The residual moisture contents 
(RMC) of BCN-NC was applied at two different stresses defined as "conservative" condition $(0<\mathrm{RMC}<1 \%)$ and "aggressive" condition $(1 \%<\mathrm{RMC}<2 \%)$, respectively. (3) Short-term (6 months) stability testing was performed to investigate the influence of stabilizers' property and storage stress on the redispersibility of BCN-NC. Storage temperature was applied at three different stress conditions defined as conservative $\left(4^{\circ} \mathrm{C}\right)$, "moderate" $\left(25^{\circ} \mathrm{C}\right)$, and aggressive $\left(40^{\circ} \mathrm{C}\right)$, respectively. (4) The influence of matrix formers on the redispersibility of drug nanocrystals at different storage stresses was investigated.

\section{MATERIALS AND METHODS}

\section{Materials}

Baicalin was purchased from Zelang Co. (Nanjing, China). TPGS was purchased from Xi'an Healthful Biotechnology Co., Ltd. (Xi'an, China). HPMC (Methocel E15LV Premium EP®, Colorcon, Dartford, UK) was commercially obtained. Polyoxyethylene hydrogenated castor oil (RH 40, Cremophor ${ }^{\circledR}$ RH 40) was kindly donated by BASF (Ludwigshafen, Germany). PVP K30 (Plasdone ${ }^{\circledR}$ K-29/32) was kindly donated by JSP (New Jersey, USA). Tween 80 (SHANHE, China), trehalose (Asahi KASEI, Japan), and CMS-Na (SHANHE, China) were commercially obtained. Sucrose and lactose were obtained from DAMAO Chemical Co., Ltd. (Tianjin, China).

\section{Production of BCN-NS I}

BCN-NS was prepared by high-pressure homogenization. Before producing BCN-NS, baicalin coarse powder $1 \%(w / v)$ was dispersed in the solution with $0.5 \%(w / v)$ of stabilizer (TPGS, RH 40, Tween 80, HPMC, and CMS-Na), respectively. Firstly, the obtained mixture was disintegrated into coarse suspensions by a high shear homogenizer (FLUKO® FA25, Essen, Germany) at 16,000 rpm for $5 \mathrm{~min}$. Secondly, then obtained coarse suspensions were homogenized using a piston-gap high-pressure homogenizer (AH-1000D, ATS Engineering Inc., Seeker, Canada). Five cycles at 500 bar were conducted as a pre-milling step, and then 20 cycles at 1000 bar were applied to obtain the fine BCN-NS I.

\section{Production of BCN-NS II}

For comparison purpose, baicalin coarse powder $1 \%(w / v)$ was dispersed in the solution with $0.1 \%(w / v)$ of stabilizer TPGS or HPMC, respectively. BCN-NS II was prepared according to the procedure as mentioned above. The resulting stock nanosuspensions were mixed with $4 \%(w / v)$ of sucrose, trehalose, lactose and PVP K30, respectively.

\section{Production of Baicalin Nanocrystals}

\section{Aggressive Condition via Spray-Drying}

The BCN-NC powders were obtained by spraying BCNNS through the nozzle of a BUCHI mini spray dryer (model B290, Buchi Laboratoriums-Technik AG, Flawil, Switzerland). The process parameters were set to allow a modulation in water content in the samples as follows: inlet temperature at $110^{\circ} \mathrm{C}-150^{\circ} \mathrm{C}$, feed flow rate at $1-5 \mathrm{ml} / \mathrm{min}$, aspiration rate at $55 \%$, and atomizing air flow at $50 \mathrm{mmHg}$. This process allowed a modulation in residual moisture in the spray-dried samples. The dried $\mathrm{BCN}-\mathrm{NC}$ powders were separated from the drying air in the cyclone $\left(57^{\circ} \mathrm{C}-83^{\circ} \mathrm{C}\right.$ outlet temperature) and deposited at the bottom of the collector. They were collected and kept at room temperature for future testing and evaluation.

\section{Conservative Condition via Freeze-Drying}

The BCN-NS stabilized by different polymeric dispersants were dried by lyophilization. Each BCN-NS (3 ml) was freeze-dried at $-40^{\circ} \mathrm{C}$ in a $10-\mathrm{ml}$ vial using a freeze dry system (FreezeZone ${ }^{\circledR}$ Stoppering Tray Dryers, LABCONCO Corporation, Kansas, USA) with 50 mbar vacuum for $24 \mathrm{~h}$. The applied cycle conditions were as follows: freezing was performed at $-40^{\circ} \mathrm{C}$ for $60 \mathrm{~min}$. The shelf temperature ramp rate from the freezing step to the primary drying step was $1{ }^{\circ} \mathrm{C} /$ min for all cycles performed. The primary drying conditions were employed at $-20^{\circ} \mathrm{C}$ for $6 \mathrm{~h}$. The shelf heating rate from the primary drying shelf set point to the secondary drying set point at $20^{\circ} \mathrm{C}$ was $0.15^{\circ} \mathrm{C} / \mathrm{min}$. Secondary drying for these cycles was performed over 2-8 h. This process allowed a modulation in residual moisture in the freeze-dried samples. The chamber pressure during primary and secondary drying was controlled at 75 mTorr throughout all experiments.

\section{Stability Evaluation}

Immediately after drying, the products $(n=3)$ were sealed and stored at $4{ }^{\circ} \mathrm{C}, 25^{\circ} \mathrm{C}$, and $40^{\circ} \mathrm{C}$, respectively. After 1,3 , and 6 months, samples were analyzed in terms of the redispersibility index (RDI).

\section{Particle Size Evaluation of BCN-NC}

The particle size and distribution of BCN-NC obtained during solidification was evaluated, using a Mastersizer Micro Plus (Malvern Instruments Limited, Worcestershire, UK). Analysis of the diffraction patterns was performed using the Mie model, with a dispersant refractive index of 1.33 .

The average $50 \%$ and $90 \%$ volume percentile $D_{50}$ and $D_{90}$ were determined, as well as the average span of the distribution

$\operatorname{Span}={ }^{\left(D_{90}-D_{10}\right)} /{ }_{D_{50}}$

\section{Determined of Residual Moisture Contents of BCN-NC}

The RMC was determined by a thermogravimetric analyzer (TGA, Q5000IR, TA Instruments, New Castle, USA). The sample weight loss was monitored as the furnace temperature increased from room temperature $\left(23^{\circ} \mathrm{C}\right)$ to $250^{\circ} \mathrm{C}$ at a program heating rate of $5^{\circ} \mathrm{C} / \mathrm{min}$. The weight of the evolved moisture was taken as the difference between the initial sample weight and the sample weight (at approximately $100^{\circ} \mathrm{C}$ ) at the horizontal region of the thermogram indicative of the attainment of constant weight. The ratio of the weight of the 
lost residual moisture to the initial sample weight multiplied by one 100 yielded the percentage RMC of the sample.

\section{Redispersibility Index}

$\mathrm{RDI}=\frac{D}{D_{0}} \times 100 \%$

Where $D_{0}$ is the redispersed particle size $\left(D_{50}\right)$ of freeze-dried/ spray-dried BCN-NC and $D$ is the reconstituted corresponding $D_{50}$ value of BCN-NC post-storage. A RDI of near $100 \%$ would generally mean that nanocrystal powder can be completely reconstituted into the original $\mathrm{BCN}-\mathrm{NS}$ after rehydration.

\section{Scanning Electron Microscopy}

The morphological evaluation of representative samples of BCN-NC was performed and compared against each other under a scanning electron microscope (SEM) (Nova Nano SEM45, FEI, USA). All samples were evaluated on a brass stub using carbon double-sided tape. The samples were gold coated (thickness $\approx 15-20 \mathrm{~nm}$ ) with a sputter coater (Fison Instruments, UK) using an electrical potential of $2.0 \mathrm{kV}$ at $25 \mathrm{~mA}$ for $10 \mathrm{~min}$.

\section{Differential Scanning Calorimetry (DSC)}

The glass transition temperature $\left(T_{\mathrm{g}}\right)$ of the samples were performed using a differential scanning calorimeter (DSC) (Diamond DSC, Perkin-Elmer, USA) equipped with an intercooler. Calibration for temperature and heat of fusion was carried out with indium and tin as reference materials. The samples were analyzed in open aluminum pans and scanned under a nitrogen purge with a heating rate of $10^{\circ} \mathrm{C} / \mathrm{min}$ from 10 to $90^{\circ} \mathrm{C}$ above the expected melting point.

\section{RESULTS}

Inherent Damage of Freeze/Spray-Dry Process on the Redispersibility of Drug Nanocrystals During Storage

The particle size of redispersed BCN-NC after drying is listed in Fig. 2. The mean particle size of prepared BCN-NS was in the range of $500 \sim 700 \mathrm{~nm}$. The morphology of the freeze-dried/spraydried BCN-NC stabilized by TPGS/Tween 80 is showed in Fig. 3, respectively. The results showed the morphology of the freezedried $\mathrm{BCN}-\mathrm{NC}$ was different with that of the spray-dried $\mathrm{BCN}$ NC. The freeze-dried BCN-NC appeared to be cotton-shaped, but the spray-dried $\mathrm{BCN}-\mathrm{NC}$ seemed to form some aggregations. But the particle size of spray-dried BCN-NC did not significantly increase, compared with that of freeze-drying.

The comparison of the redispersibility index of BCN-NC prepared by freeze-drying or spray-drying after 6 months of storage at three stresses conditions of $4^{\circ} \mathrm{C}, 25^{\circ} \mathrm{C}$, and $40^{\circ} \mathrm{C}$ stabilized by TPGS or Tween 80 is showed in Fig. 4. The results showed that the redispersibility index of freeze-dried BCN-NC stabilized by TPGS or Tween 80 was not significantly different compared with that of spray-dried BCN-NC at equivalent storage conditions. It can be observed that the redispersibility of BCN-NC was $\mathrm{RDI}_{40^{\circ} \mathrm{C}}>\mathrm{RDI}_{25^{\circ} \mathrm{C}}>\mathrm{RDI}_{4}{ }^{\circ} \mathrm{C}$ at three stress conditions, which was respectively stabilized by $50 \%$ TPGS and Tween 80 . But the redispersibility of BCN-NC stabilized by TPGS was better than that of by Tween 80 during storage conditions, which indicated that the stability of BCN-NC during storage was related with property of stabilizers.

\section{The Roles of Different Stabilizers on the Redispersibility of Drug Nanocrystals with Different RMC at Different Storage Conditions}

The RDI of BCN-NC stabilized by different stabilizers (Tween 80, TPGS, HPMC, and CMS-Na) at different storage stress conditions $\left(4^{\circ} \mathrm{C}, 25^{\circ} \mathrm{C}, 40^{\circ} \mathrm{C}\right)$ is showed in Fig. 5. A series of BCN$\mathrm{NC}$ with lower than $1 \% \mathrm{RMC}$ was successfully prepared. The results showed that the RDI of BCN-NC respectively stabilized by HPMC and CMS-NA at different storage stress conditions was less than 1.05, which indicated that the redispersibility of BCN-NC respectively stabilized by HPMC and CMS-NA was acceptable. But the RDI of BCN-NC respectively stabilized by TPGS and Tween 80 at different storage stress conditions was significantly increased (1.7-5.7), with higher storage temperature, especially at $40^{\circ} \mathrm{C}$, and the RDI of BCN-NC was significantly related with the storage time.

The RDI of BCN-NC stabilized by different stabilizers (Tween 80, TPGS, HPMC, and CMS-Na) at different storage stress conditions $\left(4^{\circ} \mathrm{C}, 25^{\circ} \mathrm{C}, 40^{\circ} \mathrm{C}\right)$ is showed in Fig. 6. It was observed that the RMC of BCN-NC stabilized by different stabilizers (Tween 80, TPGS, HPMC, and CMS-Na) was between $1 \%$ and $2 \%$. But the RDI of BCN-NC respectively stabilized by TPGS and Tween 80 at different storage stress conditions was significantly increased, respectively, compared with that of $\mathrm{BCN}-\mathrm{NC}(0<\mathrm{RMC}<1 \%)$ at equivalent storage temperature, especially at $25^{\circ} \mathrm{C}$ (moderate stress). The DSC curves of BCN-NC stabilized by different stabilizers (TPGS/ Tween 80/RH 40/HPMC/CMS-Na) with different stresses of RMC are showed in Fig. 7.

The Roles of Matrix Formers on the Redispersibility of Drug Nanocrystals at Different Storage Conditions

The RDI of BCN-NC/TPGS with different matrix formers (sucrose, lactose, trehalose, and PVP K30) at different storage stress conditions $\left(4^{\circ} \mathrm{C}, 25^{\circ} \mathrm{C}, 40^{\circ} \mathrm{C}\right)$ is showed in Figs. 8 and 9. Figure 10 shows the DSC results of BCN-NC/TPGS with different matrix formers, which indicated that BCN-NC/TPGS/lactose and BCN-NC/TPGS/PVP K30 with high RMC had vitrification transformation at $38^{\circ} \mathrm{C}-40^{\circ} \mathrm{C}$ and the $T_{\mathrm{g}}$ of $\mathrm{BCN}-$ $\mathrm{NC} / \mathrm{TPGS} /$ sucrose and BCN-NC/TPGS/trehalose with higher RMC seemed to be more lower (Fig. 10a), compared with those of low RMC (Fig. 10b). These results illustrated that BCN-NC/ TPGS/PVP K30 with relative high RMC had some significant aggregation of crystals, compared with those of low RMC.

\section{DISCUSSIONS}

\section{Inherent Damage of Freeze/Spray-Dry Process on the Redispersibility of Drug Nanocrystals During Storage}

Compared with freeze-drying, spray-drying was a rapid process for generating nanocrystal powder in which a feed solution containing the drug nanosuspensions is atomized into 


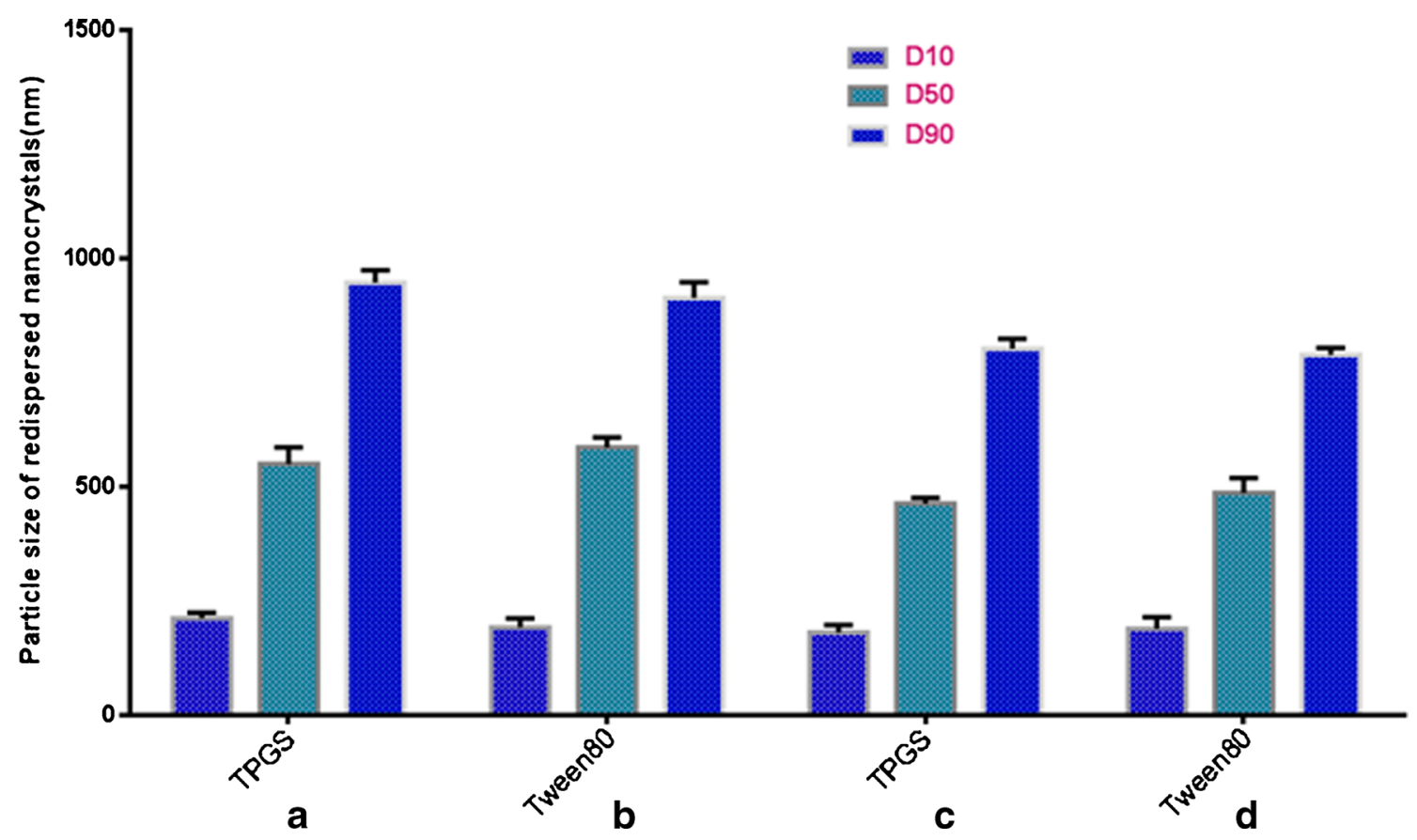

Fig. 2. The particle size of BCN-NC prepared by freeze-drying and spray-drying. a Freeze-dried BCN-NC/TPGS, b freezedried BCN-NC/Tween 80, $\mathbf{c}$ spray-dried BCN-NC/TPGS, and d spray-dried BCN-NC/TPGS

droplets that rapidly dry due to their high surface area and intimate contact with drying air $(6,22,23)$. The temperature strength used in spray-drying is usually more aggressive (higher than $100^{\circ} \mathrm{C}$ ) compared with that used in freezedrying (lower than $30^{\circ} \mathrm{C}$ ). However, the dry time of spraydrying used is shorter (40-50 s) than that of freeze-drying (24-

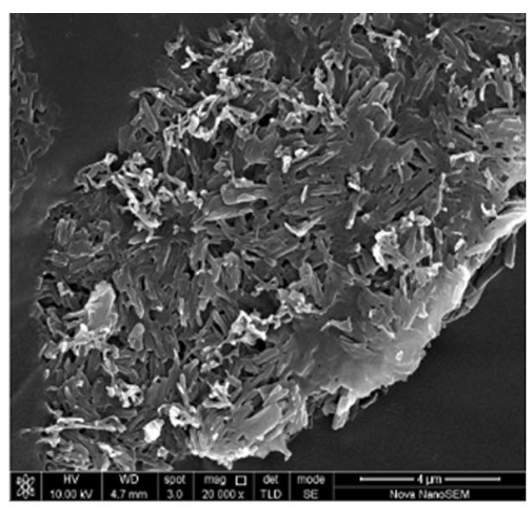

a

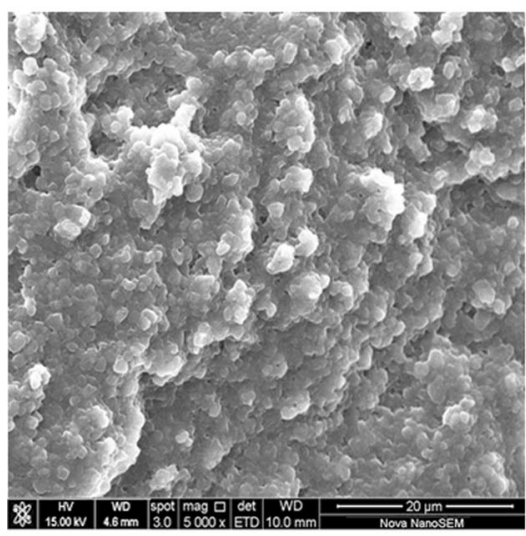

C

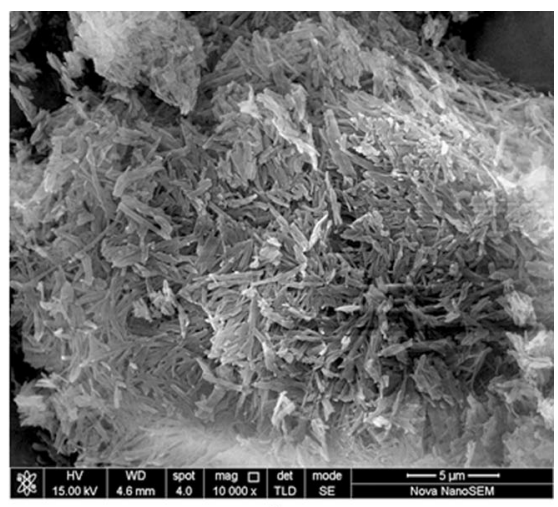

b

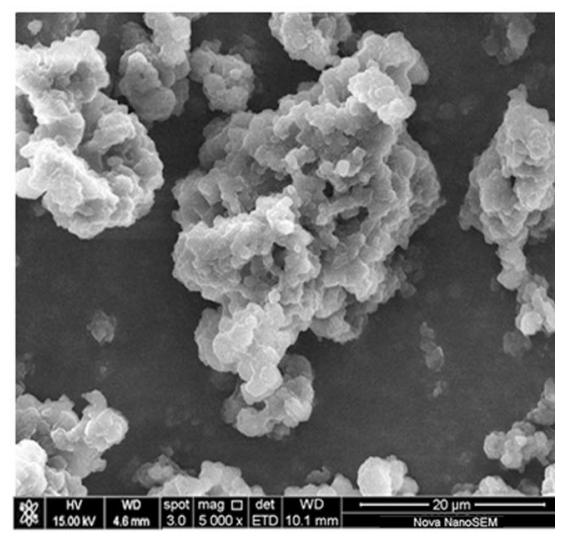

d

Fig. 3. The morphology of BCN-NC after drying. a Freeze-dried BCN-NC/TPGS, b freezedried BCN-NC/Tween 80, $\mathbf{c}$ spray-dried BCN-NC/TPGS, and $\mathbf{d}$ spray-dried BCN-NC/TPGS 


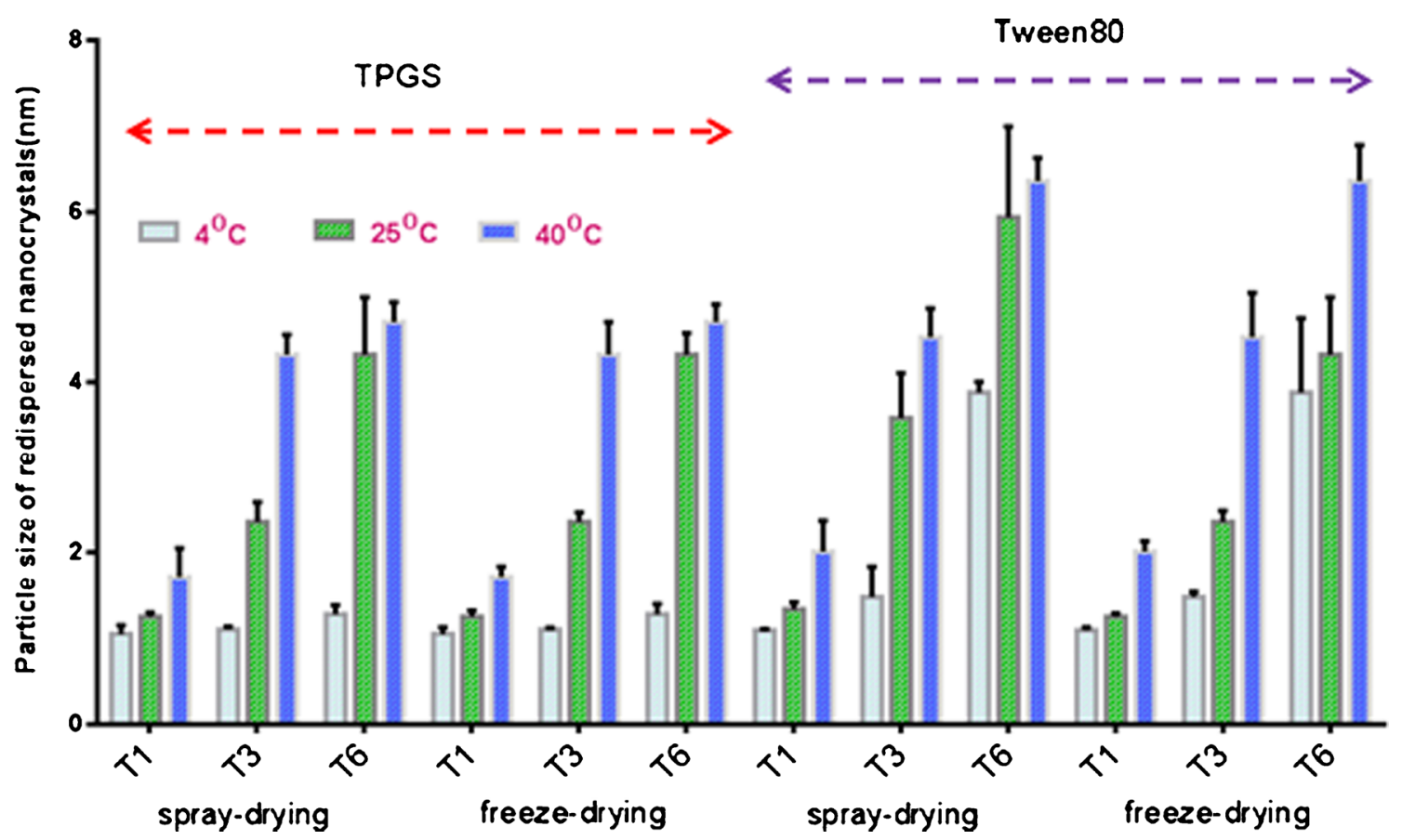

Fig. 4. Redispersibility comparison of spray-dried BCN-NC and freeze-dried BCN-NC stabilized by TPGS and Tween 80, stored for 6 months at three conditions of $4^{\circ} \mathrm{C}, 25^{\circ} \mathrm{C}$, and $40^{\circ} \mathrm{C}$, respectively

$48 \mathrm{~h}$ ). These processes may generate some stresses (due to freeze or heat), which could inevitably induce some inherent damage (such as vitrification of stabilizer TPGS and Tween $80)$ on storage stability of drug nanocrystals (14,24-26). So the inherent damage of different drying processes on the redispersibility of drug nanocrystals during storage was systemically investigated in this manuscript.

BCN-NS stabilized by TPGS and Tween 80 was successfully conversed into nanocrystals via freeze-drying and spray-drying, respectively. The results demonstrated that the BCN-NC stabilized in terms of TPGS and Tween 80 could be completely

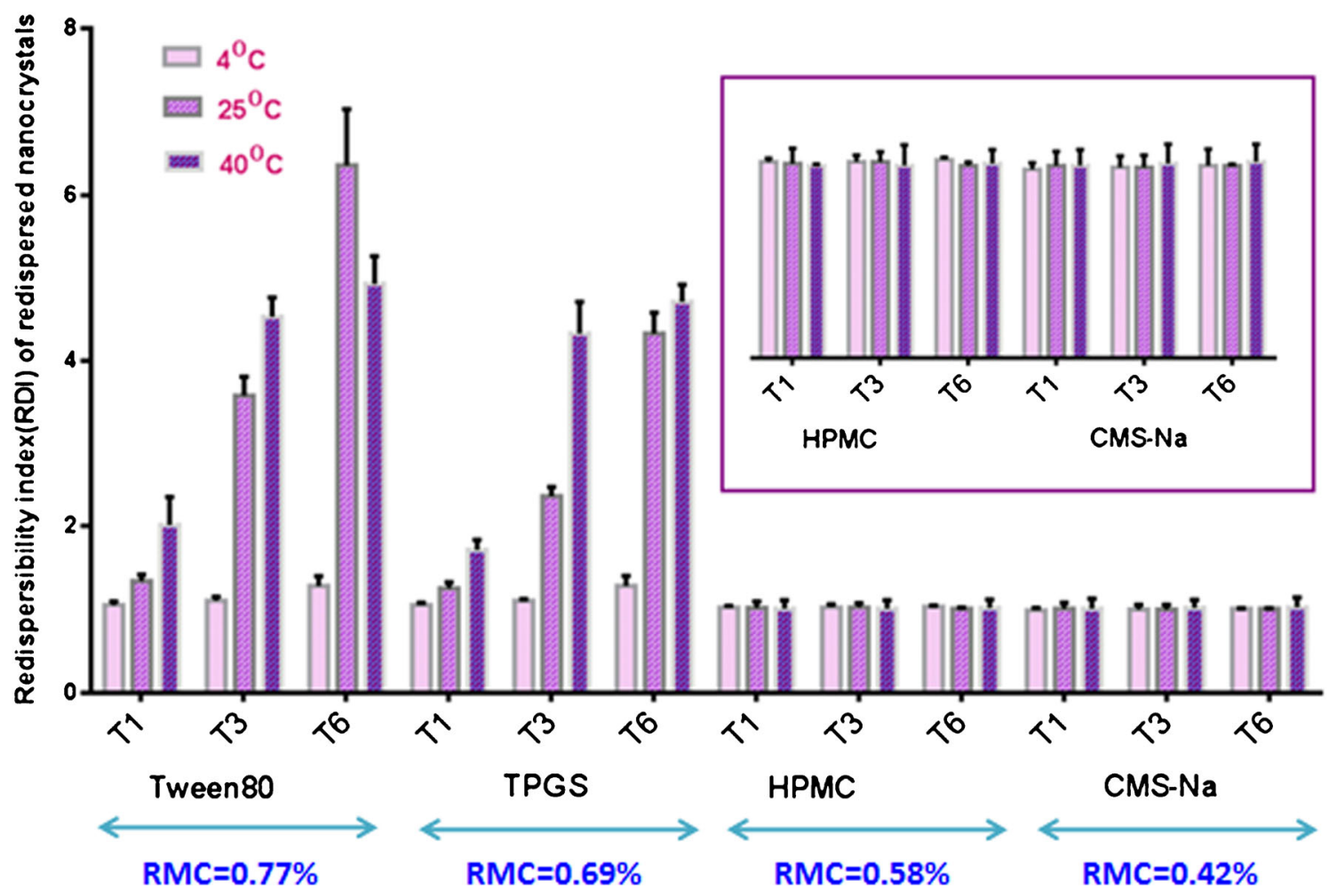

Fig. 5. The redispersibility of $\mathrm{BCN}-\mathrm{NC}(0<\mathrm{RMC}<1 \%)$ stabilized by different stabilizers (Tween 80 , TPGS, HPMC, and CMS-Na) at different storage stress conditions $\left(4^{\circ} \mathrm{C}, 25^{\circ} \mathrm{C}, 40^{\circ} \mathrm{C}\right)$ 


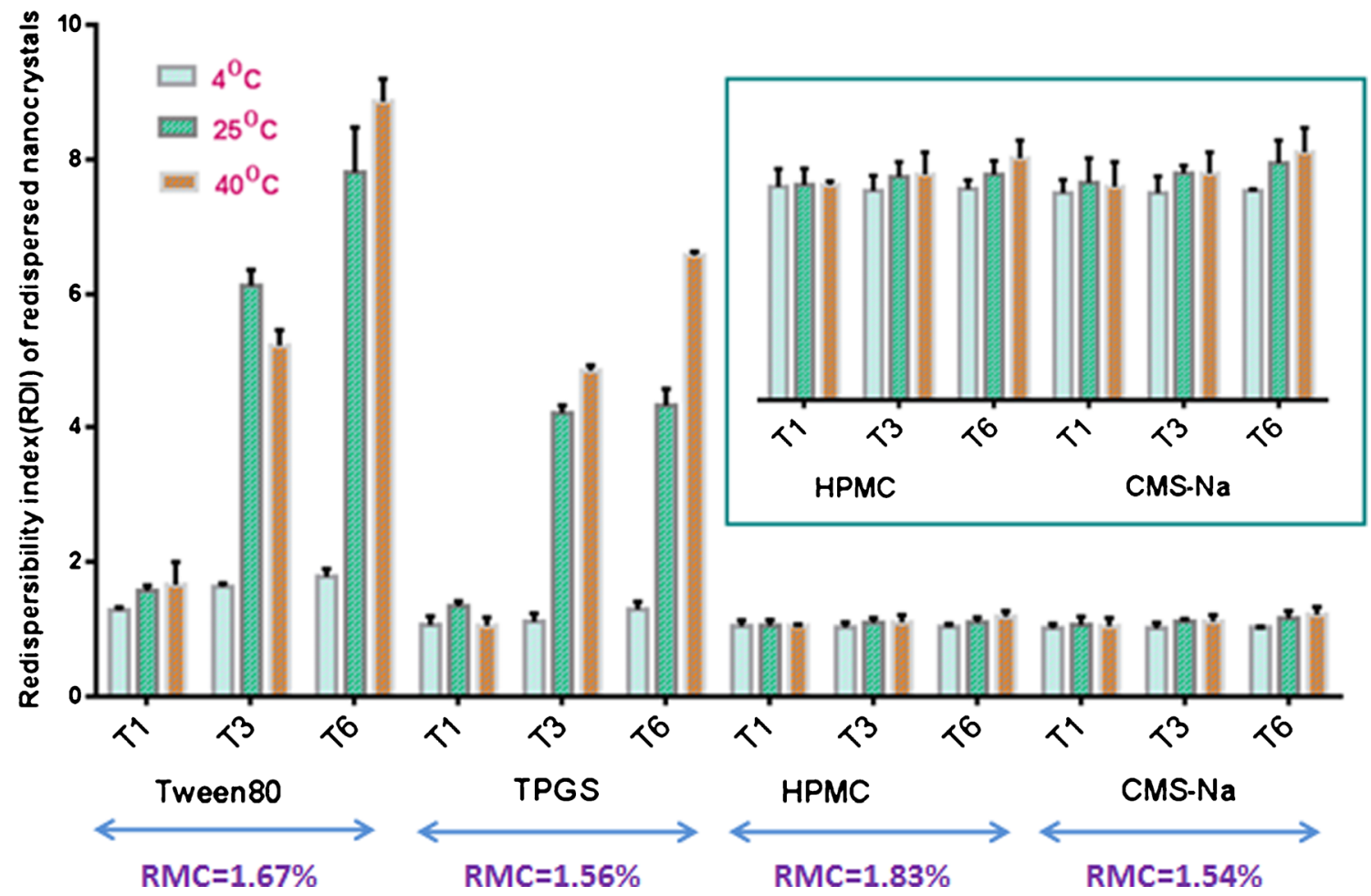

Fig. 6. The redispersibility of BCN-NC $(1 \%<\mathrm{RMC}<2 \%)$ stabilized by different stabilizers (Tween 80 , TPGS, HPMC, and CMS-Na) at different storage stress conditions $\left(4^{\circ} \mathrm{C}, 25^{\circ} \mathrm{C}, 40^{\circ} \mathrm{C}\right)$

redispersed into original nanosuspensions. The morphology of the freeze-dried/spray-dried BCN-NC stabilized by TPGS/ Tween 80 illustrated that the spray-dried BCN-NC had been vitrified/fused due to spray-drying temperature higher than glass transition temperature/melting point of TPGS and Tween 80 (Fig. 3). But the particle size of spray-dried BCN-NC did not significantly increase, compared with that of freeze-drying. This indicated that transient vitrification of $\mathrm{BCN}-\mathrm{NC}$ during spraydrying seemed to not result in irreversible aggregation of nanocrystals, but this did not mean that vitrification for a long time was not responsible for aggregation of nanocrystals, especially during storage $(27,28)$. A comparison of BCN-NC prepared by freeze-drying or spray-drying after 6 months of storage at three stress conditions of $4{ }^{\circ} \mathrm{C}, 25^{\circ} \mathrm{C}$, and $40^{\circ} \mathrm{C}$ stabilized by TPGS or Tween 80 showed that the redispersibility index of freeze-dried BCN-NC stabilized by TPGS or Tween 80 was not significantly different compared with those of spraydried BCN-NC at equivalent storage conditions (Fig. 4). This indicated that inherent stresses from freeze-drying/spray-drying process seemed not to be a prerequisite for the redispersibility of $\mathrm{BCN}-\mathrm{NC}$ during storage. But the results demonstrated that the different storage stresses induced various damages to the pro-

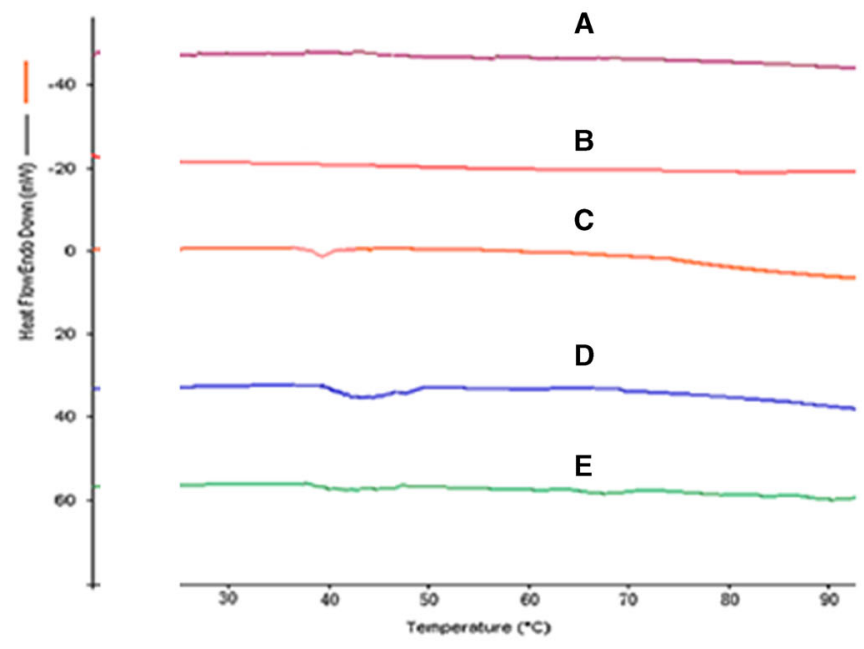

a

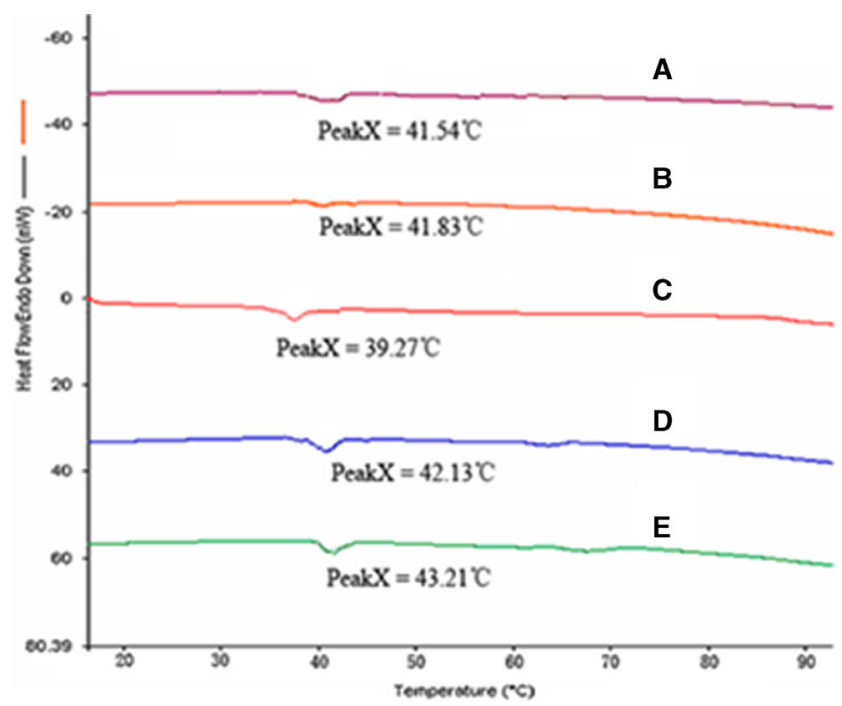

b

Fig. 7. a, b Thermograms of prepared BCN-NC/TPGS $(A), \mathrm{BCN}-\mathrm{NC} / \mathrm{HPMC}(B), \mathrm{BCN}-\mathrm{NC} / \mathrm{Tween} 80(C), \mathrm{BCN}-\mathrm{NC} / \mathrm{RH} 40(D)$, and BCN-NC/ CMS-Na $(E)$ 


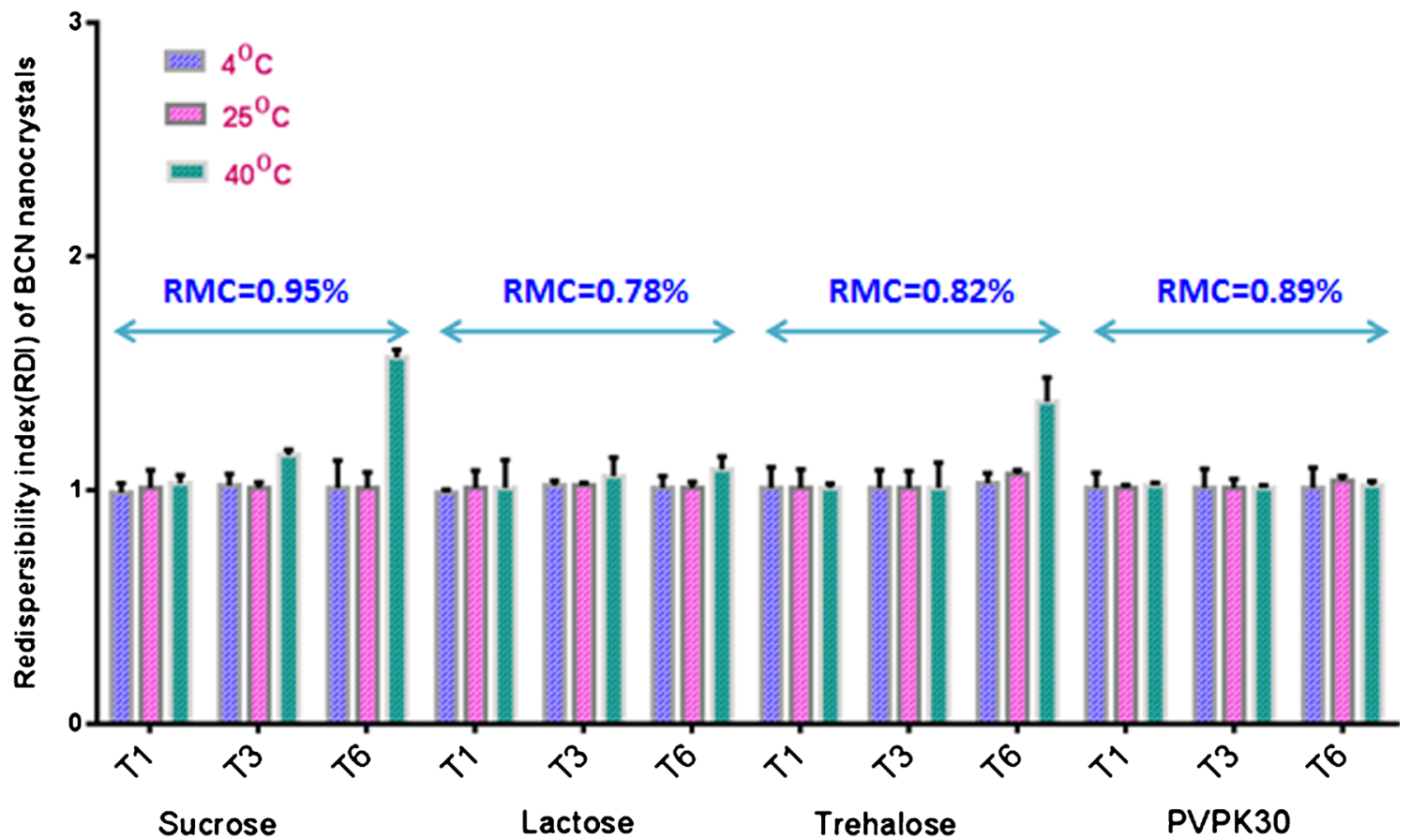

Fig. 8. The redispersibility of BCN-NC/TPGS $(0<\mathrm{RMC}<1 \%)$ with different matrix formers (sucrose, lactose, trehalose, and PVP K30) at different storage stress conditions $\left(4^{\circ} \mathrm{C}, 25^{\circ} \mathrm{C}, 40^{\circ} \mathrm{C}\right)$

tection effect of stabilizers and then promote the irreversible aggregation of BCN-NC during storage.

The Roles of Different Stabilizers on the Redispersibility of Drug Nanocrystals with Different RMC

Vitrification of BCN-NC might be related with the stabilizer type and residual moisture, which could be responsible for aggregation of BCN-NC during storage $(29,30)$. To prove the roles of stabilizers and residual moisture on the redispersibility of $\mathrm{BCN}-\mathrm{NC}$ at different storage conditions, the spray-dried BCN-NC with different RMC stabilized by HPMC, CMS-Na, TPGS and Tween 80 was investigated at different storage conditions.

The comparison of the RDI of BCN-NC stabilized by different stabilizers (Tween 80, TPGS, HPMC, and CMS-Na)

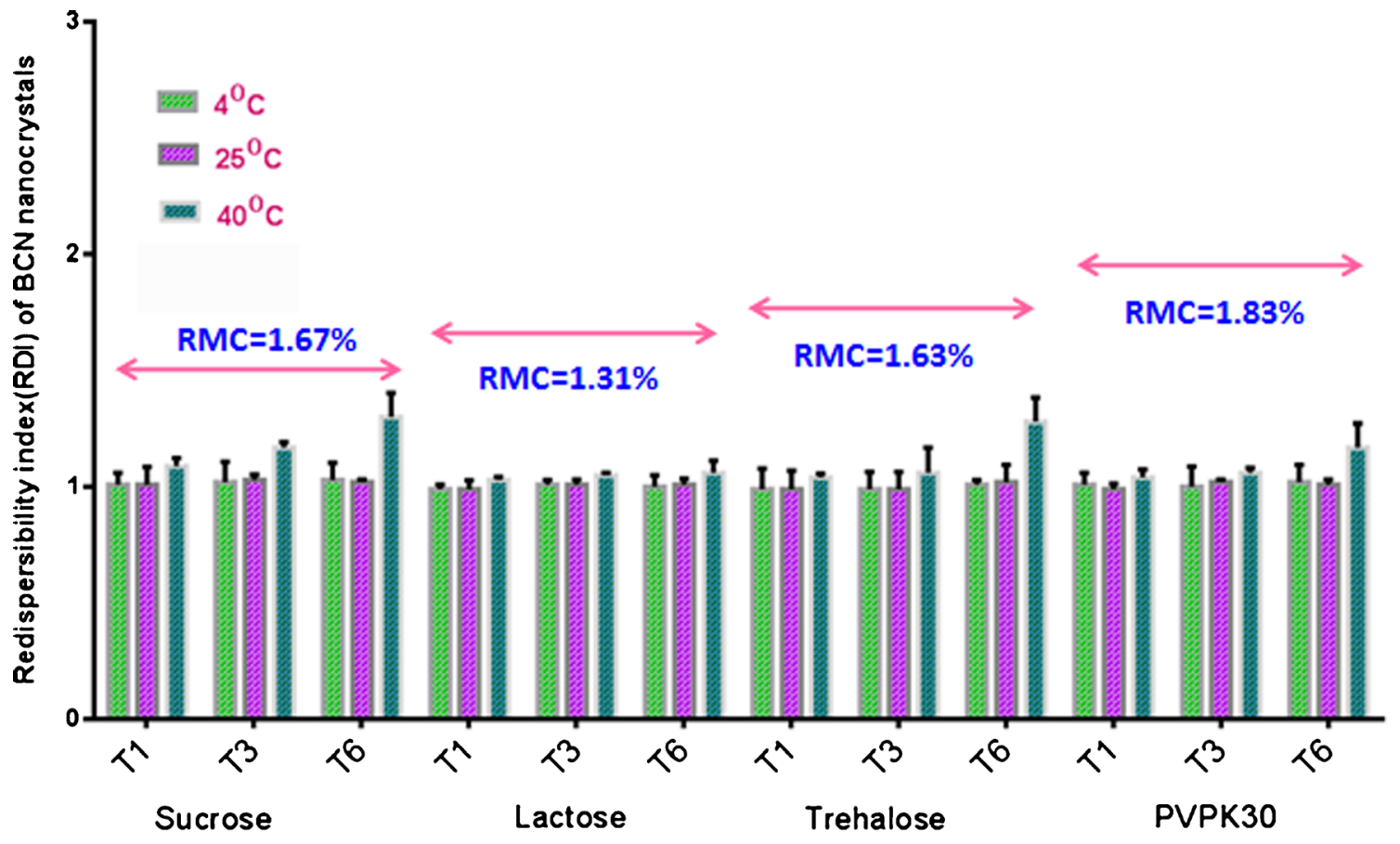

Fig. 9. The redispersibility of BCN-NC/TPGS $(1 \%<\mathrm{RMC}<2 \%)$ with different matrix formers (sucrose, lactose, trehalose and PVP K30) at different storage stress conditions $\left(4^{\circ} \mathrm{C}, 25^{\circ} \mathrm{C}, 40^{\circ} \mathrm{C}\right)$ 

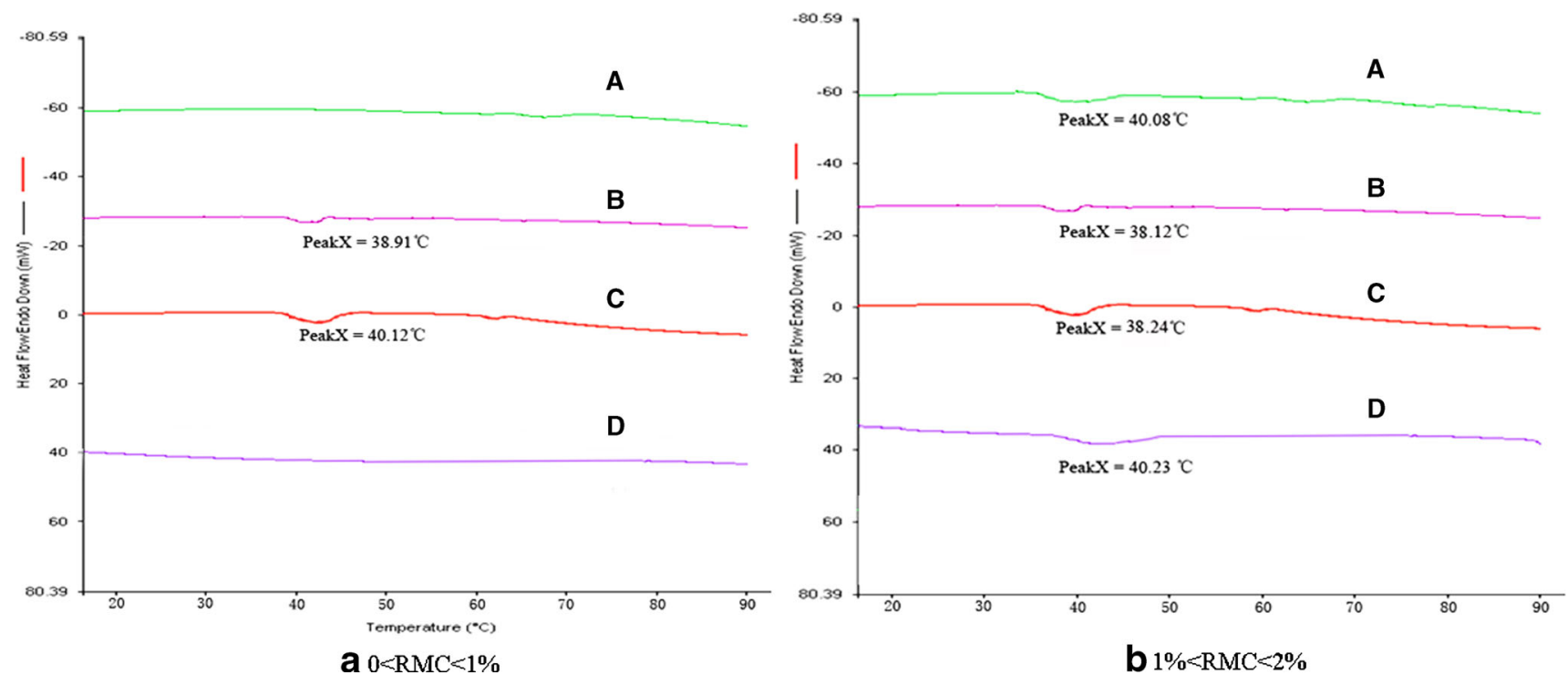

Fig. 10. a, b DSC results of BCN-NC/TPGS with different matrix formers BCN-NC/TPGS/lactose $(A), \mathrm{BCN}-\mathrm{NC} / \mathrm{TPGS} / \mathrm{sucrose}(B), \mathrm{BCN}-\mathrm{NC} / \mathrm{TPGS} /$ trehalose $(C)$, and BCN-NC/TPGS/PVP K30 $(D)$

at different storage stress conditions $\left(4^{\circ} \mathrm{C}, 25^{\circ} \mathrm{C}, 40^{\circ} \mathrm{C}\right)$ is showed in Figs. 5 and 6. The results showed that the RDI of $\mathrm{BCN}-\mathrm{NC} / \mathrm{HPMC}$ and $\mathrm{BCN}-\mathrm{NC} / \mathrm{CMS}-\mathrm{NA}$ at different storage stress conditions was not significantly increased, which indicated that polymer stabilizers HPMC and CMS-NA possessed an excellent performance for redispersibility of BCN-NC during storage, even in higher residual moisture. But the RDI of BCN-NC $(1<\mathrm{RMC}<2 \%)$ respectively stabilized by TPGS, Tween 80 , or RH 40 at different storage stress conditions was significantly increased compared with that of BCN-NC $(0<\mathrm{RMC}<1 \%)$ at equivalent storage temperature, especially at $25^{\circ} \mathrm{C}$ (moderate stress). These demonstrated that the existence of high RMC could exacerbate aggregation of nanocrystals during storage (31-33). Figure 7 shows that a slight increase in moisture adsorption could significantly reduce $T_{\mathrm{g}}$ of nanocrystal powder samples. Therefore, the endothermic peak for vitrification did not appear in $\mathrm{BCN}-\mathrm{NC} /$ $\mathrm{HPMC}$ and $\mathrm{BCN}-\mathrm{NC} / \mathrm{CMS}-\mathrm{Na}$ with conservative RMC $(<1 \%)$, but in BCN-NC/HPMC and BCN-NC/CMS-Na with aggressive residual moisture, $(2 \%>\mathrm{RMC}>1 \%)$ endothermic peak appeared at near $40^{\circ} \mathrm{C}$. During storage, the aggressive storage temperature $\left(40^{\circ} \mathrm{C}\right)$ had reached $T_{\mathrm{g}}$ of BCN-NC. So in BCN-NC/Tween 80, BCN-NC/TPGS, and BCN-NC/RH 40, endothermic peak for vitrification appeared. It was the reason that water had a strong plasticizing effect and could significantly lower the glass transition temperature of polymers and induce its vitrification transition at relatively lower temperature (34). The dependence of glass transition temperature $\left(T_{\mathrm{g}}\right)$

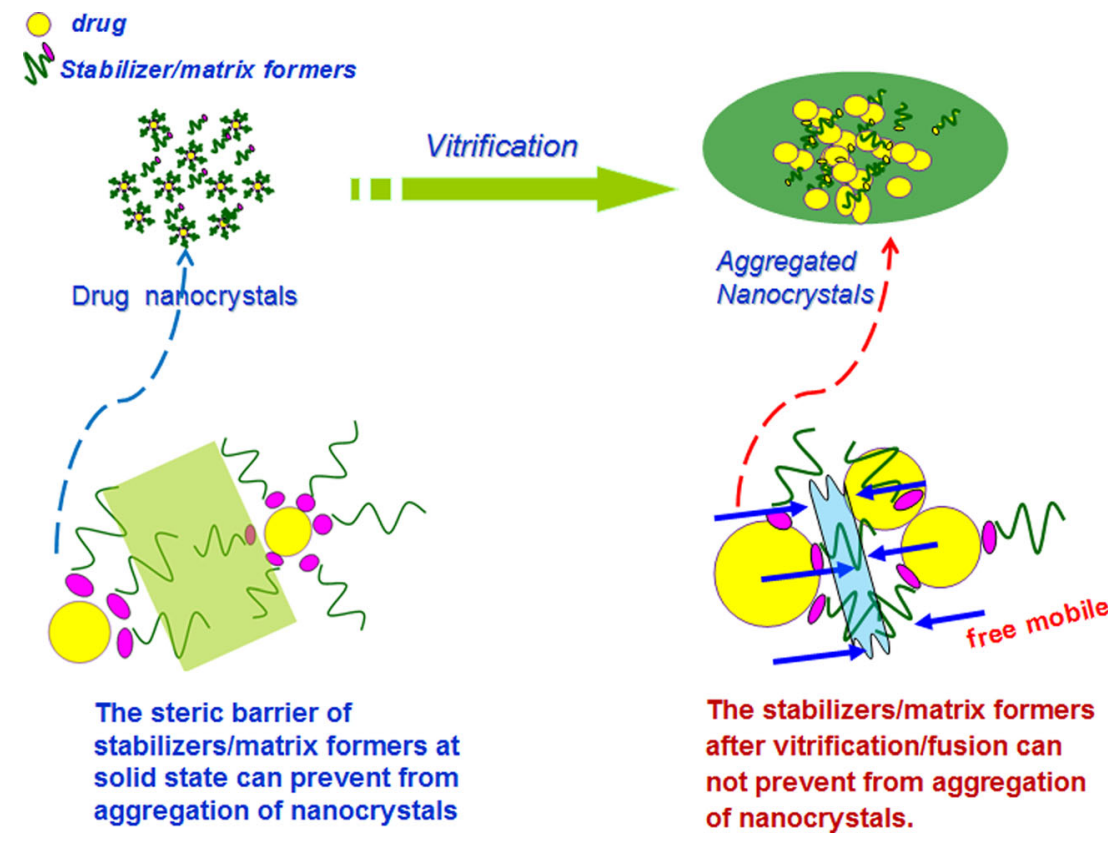

Fig. 11. The schematic illustration of drug nanocrystal aggregation induced by vitrification of stabilizers/matrix formers during storage 
on the residual water content can be demonstrated by the Gordon-Taylor equation (35):

$$
T_{\mathrm{g}}=\frac{w_{\mathrm{s}} T_{\mathrm{g}_{s}}+k w_{\mathrm{w}} T_{\mathrm{g}_{\mathrm{w}}}}{w_{\mathrm{s}}+k w_{\mathrm{w}}}
$$

where $T_{\mathrm{g}}, T_{\mathrm{gs}}$, and $T_{\mathrm{gw}}$ are the glass transition temperatures of the binary mixture, dry matter, and water, respectively. The $T_{\mathrm{gw}}$ value was taken as $-135^{\circ} \mathrm{C} . w_{\mathrm{s}}$ and $w_{\mathrm{w}}$ are the weight fractions of dry matter and water, respectively. $k$ is the arithmetic average of a series of $k$ values that were obtained by solving the equation for a series of binary systems with water and dry matter at different ratios.

\section{The Roles of Matrix Formers on the Redispersibility of Drug Nanocrystals at Different Storage Conditions}

Vitrification of BCN-NC might also be related with the matrix former type and residual moisture (36-38). To prove the roles of matrix formers and residual moisture on the redispersibility of drug nanocrystals at different storage conditions, the redispersibility of BCN-NC/TPGS with matrix formers and different RMC was systemically investigated.

The RDI of BCN-NC/TPGS/sucrose and BCN-NC/ TPGS/trehalose stored at aggressive $40^{\circ} \mathrm{C}$ for 6 months was significantly increased, compared with those stored at $4^{\circ} \mathrm{C}$ and $25^{\circ} \mathrm{C}$, respectively. But the RDI of BCN-NC/TPGS/lactose and $\mathrm{BCN}-\mathrm{NC} / \mathrm{TPGS} / \mathrm{PVP} \mathrm{K} 30$ stored at $40^{\circ} \mathrm{C}$ for 6 months was not significantly increased. Figure $10 \mathrm{a}$ shows that the vitrification phenomenon of BCN-NC/TPGS/sucrose and $\mathrm{BCN}-\mathrm{NC} / \mathrm{TPGS} /$ trehalose appeared at $38-40^{\circ} \mathrm{C}$ (near to $40^{\circ} \mathrm{C}$ as aggressive storage temperature), while $\mathrm{BCN}-\mathrm{NC} /$ TPGS/lactose and BCN-NC/TPGS/PVP K30 did not have vitrification phenomenon. These demonstrated that vitrification of BCN-NC with matrix former system could be responsible for aggregation of BCN-NC during storage, and the influence of vitrification on aggregation of $\mathrm{BCN}-\mathrm{NC}$ was dependent on time and temperature stress. The RDI of $\mathrm{BCN}$ NC/TPGS/sucrose, BCN-NC/TPGS/trehalose, BCN-NC/ TPGS/lactose, and BCN-NC/TPGS/PVP K30 stored at aggressive $40^{\circ} \mathrm{C}$ for 6 months was significantly increased, compared with those stored at $4^{\circ} \mathrm{C}$ and $25^{\circ} \mathrm{C}$ for 6 months, respectively (Fig. 9). But the RDI of BCN-NC/TPGS/sucrose, BCN-NC/ TPGS/trehalose, BCN-NC/TPGS/lactose, and BCN-NC/ TPGS/PVP $\mathrm{K} 30$ stored at $40^{\circ} \mathrm{C}$ for 1 month was not significantly varied. Figure $10 \mathrm{~b}$ shows that the vitrification transformation of BCN-NC/TPGS/lactose and BCN-NC/TPGS/PVP $\mathrm{K} 30$ with high $\mathrm{RMC}$ appeared at $38^{\circ} \mathrm{C}-40^{\circ} \mathrm{C}$, and the $T_{\mathrm{g}}$ of $\mathrm{BCN}-\mathrm{NC} / \mathrm{TPGS} /$ sucrose and BCN-NC/TPGS/trehalose with high RMC seemed to be lower (Fig. 10b), compared with those of low RMC (Fig. 10a). It could be seen that in the absence of high relative RMC, the glass transition temperature of nanocrystal powder was decreased. It could be concluded that vitrification of $\mathrm{BCN}-\mathrm{NC}$ with matrix formers system could be responsible for aggregation of BCN-NC during storage, and the influence of vitrification on aggregation of $\mathrm{BCN}-\mathrm{NC}$ was dependent on storage time, temperature, and residual moisture $(39,40)$. It was the reason that as the storage temperature increased above $T_{\mathrm{g}}$ of matrix formers, various changes such as increase of free volume and specific heat, as well as decrease of viscosity, might be noticed. These factors controlled various time-dependent structural transformations of nanocrystals, such as stickiness, collapse, and crystallization during storage.

To sum up, storage stress conditions had a significant influence on the redispersibility of BCN-NC. As illustrated in Fig. 11, the vitrification of stabilizers/matrix formers might be responsible for aggregation of drug nanocrystals during storage. The nanocrystals would be "mobile" and had opportunity to form some aggregates again, due to collapse of internanocrystal steric barrier. The damage effect from vitrification was dependent on temperature and time, which could be calculated according to the equation as follows:

$$
E \propto k \times\left|T-T_{\mathrm{g}}\right| \times t
$$

where $E$ represents the damage effect from vitrification. $K$ represents aggregation index, which was related with the properties of stabilizers. $T$ represents storage temperature. $T_{\mathrm{g}}$ represents the glass transition temperature of drug nanocrystals, which has a negative relation with the residual moisture (Gordon-Taylor equation); $t$ represents storage time.

It was concluded that aggressive storage temperature and residual moisture could be unfavorable factors for stability of drug nanocrystals, due to exacerbation of vitrification of drug nanocrystals. The polymeric stabilizers with high $T_{\mathrm{g}}$ (HPMC and CMS-Na) possessed more excellent performance in protecting the $\mathrm{BCN}-\mathrm{NC}$ from breakage during storage, compared to the surfactants Tween 80, TPGS, or RH 40. Besides, the matrix formers with high $T_{\mathrm{g}}$ were suitable for maintaining the redispersibility of BCN-NC, such as PVP K30 and lactose.

\section{CONCLUSION}

Baicalin nanocrystal nanosuspensions were converted into baicalin nanocrystals (BCN-NC) via freeze-drying and spray-drying, respectively. The influence of different drying methods and storage stresses on the redispersibility of drug nanocrystals was investigated. The results demonstrated that the particle size of BCN-NC prepared via spray-drying did not significantly increase, compared with that of freeze-drying. The storage stress conditions had a significant influence on the redispersibility of BCN-NC. The vitrification of stabilizers/ surfactants could be responsible for aggregation of drug nanocrystals during storage, which is dependent on storage temperature, storage time, as well as residual moisture. Compared to the surfactants Tween 80, TPGS, or RH 40, the polymeric stabilizers HPMC and CMS-Na with high $T_{\mathrm{g}}$ possessed more excellent performance in preventing the $\mathrm{BCN}-\mathrm{NC}$ from vitrification breakage during storage. PVP $\mathrm{K} 30$ and lactose can be used as the effective matrix formers for maintaining the redispersibility of drug nanocrystals during storage. However, as residual water has a strong plasticizing effect, even a slight increase in moisture content could significantly reduce $T_{\mathrm{g}}$ and result in degradative changes of nanocrystals. The low storage temperature and residual moisture would be suitable for stability of drug nanocrystals during storage. The relationship between the glass transition temperature and residual moisture of drug nanocrystal powder is further investigated systemically. 


\section{ACKNOWLEDGMENTS}

The authors would like to acknowledge the financial support from the National Natural Science Foundation of China (No. 81560656), the Natural Science Found of Jiangxi Province (No. 20122BAB215038), and the Scientific Research Foundation of Jiangxi Education Bureau (No. GJJ13607).

\section{REFERENCES}

1. Jinno JI, Kamada N, Miyake M, Yamada K, Mukai T, Odomi M, et al. Effect of particle size reduction on dissolution and oral absorption of a poorly water-soluble drug, cilostazol, in beagle dogs. J Control Release. 2006;111:56-64.

2. Ige PP, Baria RK, Gattani SG. Fabrication of fenofibrate nanocrystals by probe sonication method for enhancement of dissolution rate and oral bioavailability. Colloids Surf B. 2013;108:366-73.

3. Patravale VB, Date AA, Kulkarni RM. Nanosuspensions a promising drug delivery strategy. J Pharm Pharmacol. 2004;5:827-40.

4. Rabinow BE. Nanosuspensions in drug delivery. Nat Rev. 2004:3:785-96.

5. Lee J, Yu C. Critical freezing rate in freeze drying nanocrystal dispersions. J Control Release. 2006;111:185-92.

6. Kim S, Lee J. Effective polymeric dispersants for vacuum, convection and freeze drying of drug nanosuspensions. Int J Pharm. 2010;397:218-24.

7. Van Eerdenbrugh B, Vercruysse S, Martens Johan A, Vermant J, Froyen L, Van Humbeeck J, et al. Microcrystalline cellulose, a useful alternative for sucrose as a matrix former during freezedrying of drug nanosuspensions-a case study with itraconazole. Eur J Pharm Biopharm. 2008;70:590-6.

8. Yue PF, Wang Y, Wan J, Wu ZF, Hu PY, Zheng Q, et al. The research progress of preparation methods of solid nanocrystal delivery system. Acta Pharm Sin. 2012;47:1120-7.

9. Kakran M, Shegokar R, Sahoo NG, Gohla S, Li L, Müller RH. Long-term stability of quercetin nanocrystals prepared by different methods. J Pharm Pharmacol. 2012;64:1394-402.

10. Yue PF, Li Y, Wan J, Yang M, Zhu WF, Wang CH. Study on formability of solid nanosuspensions during nanodispersion and solidification: I. Novel role of stabilizer/drug property. Int J Pharm. 2013;454:269-77.

11. Yue PF, Li G, Dan JX, Wu ZF, Wang CH, Zhu WF, et al. Study on formability of solid nanosuspensions during solidification: II novel roles of freezing stress and cryoprotectant property. Int J Pharm. 2014;475:35-48.

12. Wang W. Lyophilization and development of solid protein pharmaceuticals. Int J Pharm. 2000;203:1-60.

13. Kurozawa LE, Park KJ, Hubinger MD. Effect of maltodextrin and gum arabic on water sorption and glass transition temperature of spray dried chicken meat hydrolysate protein. J Food Eng. 2009;91:287-96.

14. Syamaladevia RM, Sablania SS, Tang J, Powers J, Swanson BG. Water sorption and glass transition temperatures in red raspberry (Rubus idaeus). Thermochim Acta. 2010;503:90-6.

15. Beirowski J, Inghelbrecht S, Arien A, van Assche I, Gieseler H. Stabilization of nanosuspensions during freeze-drying: the role of vitrification (part 1). Valetta, Malta, March: Proc. 7th World Meeting on Pharmaceutics, Biopharmaceutics and Pharmaceutical Technology. 2010:8-11.

16. Beirowski J, Inghelbrecht S, Arien A, van Assche I, Gieseler H. Stabilization of nanosuspensions during freeze-drying: the role of vitrification and its practical implications (part 2). Valetta, Malta, March: Proc. 7th World Meeting on Pharmaceutics, Biopharmaceutics and Pharmaceutical Technology. 2010:8-11.

17. Yue PF, Wan J, Wang Y, Li Y, Yang M, Hu PY, et al. d-Alphatocopherol acid polyethylene glycol 1000 succinate, an effective stabilizer during solidification transformation of baicalin nanosuspensions. Int J Pharm. 2013;443:279-87.
18. Hao JF, Wang FG, Wang XD, Zhang DR, Bi YP, Gao YS, et al. Development and optimization of baicalin-loaded solid lipid nanoparticles prepared by coacervation method using central composite design. Eur J Pharm Sci. 2012;47:497-505.

19. Taiming L, Xuehua J. Investigation of the absorption mechanisms of baicalin and baicalein in rats. J Pharm Sci. 2006;95:1326-33.

20. Xing J, Chen X, Zhong D. Absorption and enterohepatic circulation of baicalin in rats. Life Sci. 2005;78:140-6.

21. Liu J, Qiu L, Gao J, Jin Y. Preparation, characterization and in vivo evaluation of formulation of baicalein with hydroxypropylB-cyclodextrin. Int J Pharm. 2006;312:137-43.

22. Saluja V, Amorij JP, Kapteyn JC, de Boer AH, Frijlink HW, Hinrichs WL. A comparison between spray drying and spray freeze drying to produce an influenza subunit vaccine powder for inhalation. J Control Release. 2010;144(2):127-33.

23. Sosnik A, Seremeta KP. Advantages and challenges of the spraydrying technology for the production of pure drug particles and drug-loaded polymeric carriers. Adv Colloid Interface Sci. 2015;223:40-54.

24. Date PV, Samad A, Devarajan PV. Freeze thaw: a simple approach for prediction of optimal cryoprotectant for freeze drying. AAPS PharmSciTech. 2010;11:304-13.

25. Yue P, Wang C, Dan J, Liu W, Wu Z, Yang M. The importance of solidification stress on the redispersibility of solid nanocrystals loaded with harmine. Int J Pharm. 2015;480(1-2):107-15.

26. Chaubal MV, Popescu C. Conversion of nanosuspensions into dry powders by spray drying: a case study. Pharm Res. 2008;25(10):2302-8.

27. Kumar S, Gokhale R, Burgess DJ. Sugars as bulking agents to prevent nano-crystal aggregation during spray or freeze-drying. Int J Pharm. 2014;471:303-11.

28. Kakran M, Shegokar R, Gopal NS, Gohla S, Li L, Müller RH. Long-term stability of quercetin nanocrystals prepared by different methods. J Pharm Pharmacol. 2012;64:1394-402.

29. Shrestha AK, Howes T, Adhikari BP, Bhandari BR. Water sorption and glass transition properties of spray dried lactose hydrolysed skim milk powder. LWT - Food Sci Technol. 2007;40(9):1593-600.

30. Shrestha AK, Ua-arak T, Adhikari BP, Howes T, Bhandari BR. Glass transition behavior of spray dried orange juice powder measured by differential scanning calorimetry (DSC) and thermal mechanical compression test (TMCT). Inter J Food Prop. 2007;10(3):661-73.

31. Palzer S. Agglomeration of pharmaceutical, detergent, chemical and food powders-similarities and differences of materials and processes. Powder Technol. 2011;206:2-17.

32. Hartmann M, Palzer S. Caking of amorphous powders-material aspects, modelling and applications. Powder Technol. 2011;206:112-21.

33. Quek SY, Chok NK, Swedlund P. The physicochemical properties of spray-dried watermelon powder. Chem Eng Processing. 2007;46(5):386-92.

34. Tonon RV, Baroni AF, Brabet C, Gibert O, Pallet D, Hubinger MD. Water sorption and glass transition temperature of spray dried açai (Euterpe oleracea Mart.) juice. J Food Eng. 2009;94:215-21.

35. Wang W, Zhou WB. Water adsorption and glass transition of spray-dried soy sauce powders using maltodextrins as carrier. Food Bioprocess Technol. 2013;6:2791-9.

36. Cano-Chauca M, Stringheta PC, Ramos AM, Cal-Vidal J. Effect of the carriers on the microstructure of mango powder obtained by spray drying and its functional characterization. Innov Food Sci Emerg. 2005;5(4):420-8.

37. Gabas AL, Telis VRN, Sobral PJA, Telis-Romero J. Effect of maltodextrin and arabic gum in water vapor sorption thermodynamic properties of vacuum dried pineapple pulp powder. J Food Eng. 2007;82(2):246-52.

38. Righetto AM, Netto FM. Effect of encapsulating materials on water sorption, glass transition and stability of juice from immature acerola. Int J Food Prop. 2005;8(2):337-46.

39. Moraga G, Martínez-Navarrete N, Chiralt A. Water sorption isotherms and glass transition in strawberry. J Food Eng. 2004;62(4):315-21.

40. Moraga G, Martínez-Navarrete N, Chiralt A. Water sorption isotherms and phase transitions in kiwifruit. J Food Eng. 2006;72(2):147-56. 